\title{
Farewell to Donald Petersen (April 14, 1929 to Feb 28, 2010)
}

We would like to take this opportunity to say farewell to our ICDD member, Dr. Donald Petersen, and to thank him for his many years' efforts of collecting and editing the meeting calendars for Powder Diffraction. The calendar events that he compiled have been extremely useful for the diffraction community worldwide, and it has added much value to the journal all these years. We are very saddened by his passing on Feb. 28, 2010 (He was 80 years old), at Bickford Cottage, Midland, Michigan.

Dr. Petersen was raised and educated in Manitowoc, Wisconsin. He earned his B.Sc. degree from Lawrence College in Appleton, WI, and obtained his Ph.D. degree from the California Institute of Technology. Upon graduation, he worked as a research chemist for Dow Chemical until his retirement. After retirement, he founded Greenleaf Associates.

Dr. Petersen was very active at ICDD and the scientific community for many years. In addition to being the meeting calendar editor, he was the chair of the Target Systems Subcommittee and a member of the ICDD Publication Review Committee. He was also a technical editor for the Journal of Testing \& Evaluation.

In addition to his many scientific contributions, he assumed a number of key civic duties. He served as a member of the Midland Public School Board of Education. He was also an eagle scout, a scout leader, a member of the Kwanis Club of Midland, and a member of the Midland Center for the Arts Art Council. He received many awards for his services. For example, he received the Silver Beaver Award, which is the highest recognition awarded to adults for distinguished service to youth, and the Wood Badge award for leadership training in scouting.

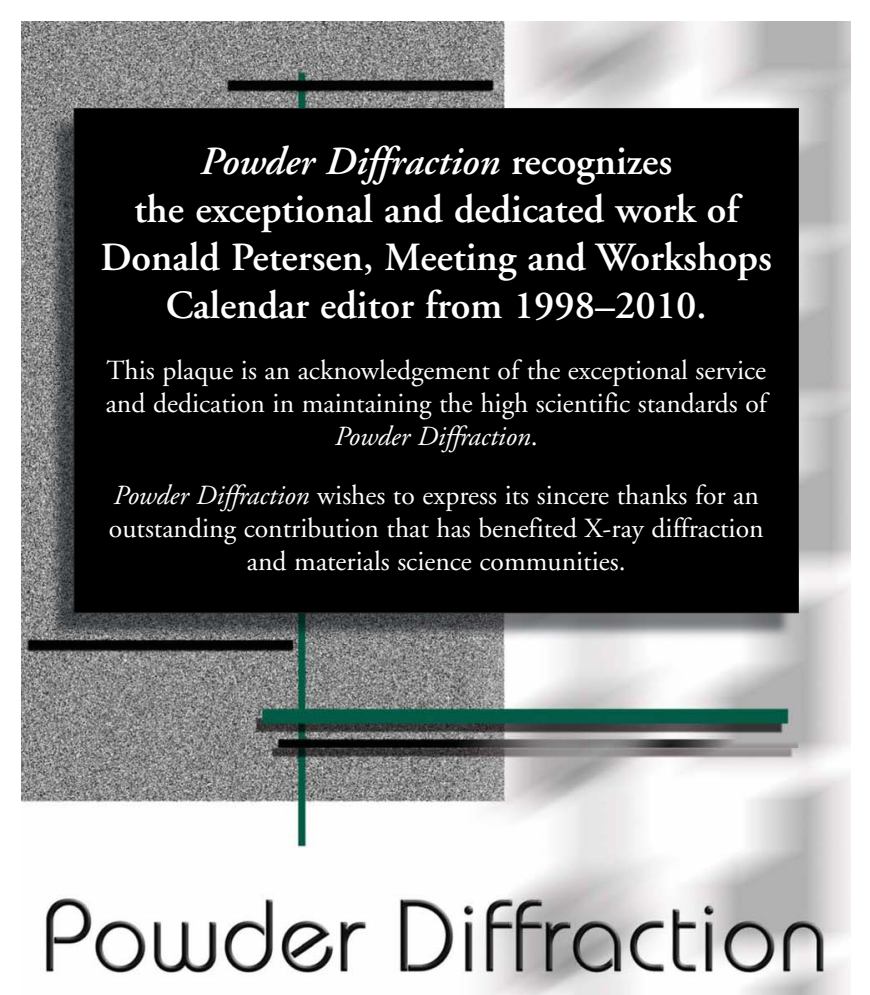

AN INTERNATIONAL JOURNAL OF MATERIALS CHARACTERIZATION

For Dr. Petersen's significant contribution to Powder Diffraction, ICDD has presented him with a plaque of appreciation. He will be missed by all of us.

Winnie Wong-Ng Editor for International Reports National Institute of Technology 